\title{
High mobility group B1 levels in sepsis and disseminated intravascular coagulation
}

\author{
Zeynep M Eskici', Şerefden Açıkgöz1凶 ${ }^{凶}$, Nihal Pişkin², Görkem Mungan1, Murat Can', \\ Berrak Güven' and Fürüzan Köktürk ${ }^{3}$
}

1Department of Biochemistry, 2Department of Infectious Diseases, 3Department of Biostatistics, Zonguldak Karaelmas University, Faculty of Medicine, Esenköy-Kozlu-Zonguldak, Turkey

Cytokines trigger coagulant and fibrinolytic systems in sepsis to result in Disseminated Intravascular Coagulation (DIC) that is an important complication and leads to disseminated hemorrhages and multi-organ failure. High Mobility Group B1 DNA Binding (HMGB1) protein is a cytokine taking part in systemic inflammatory response. The objective of this study was to investigate HMGB1 levels in groups of septic patients with and without DIC. Twenty-one septic patients without DIC and 12 septic patients with DIC from the Intensive Care Unit (ICU) were included in the study. In addition, 20 patients admitted to the ICU without sepsis or DIC and 20 healthy volunteers served as controls. Levels of HMGB1, prothrombin time, activated partial thromboplastin time, fibrinogen, D-dimer, protein C, protein S, anti-thrombin III (ATIII), platelet (thrombocyte) and leukocyte count were determined. Levels of fibrinogen, protein C, ATIII and platelet count were significantly lower and D-dimer was significantly higher in the group with sepsis plus DIC compared to the group with sepsis without DIC. Levels of HMGB1 were higher in the group with sepsis and DIC compared to the group with sepsis; however, the difference was not statistically significant and the levels of HGMB1 of both groups were significantly higher compared to ICU and healthy control groups. HMGB1 levels were not significantly different in survivor and non survivor patients. HMGB1 levels did not differ in lower respiratory tract infection (LRTI) and urinary tract infection (UTI) in regard to the etiology of sepsis.

Key words: sepsis, disseminated intravascular coagulation, HMGB1

Received: 08 Jnauary, 2012; revised: 21 September, 2012; accepted: 15 October, 2012; available on-line: 23 October, 2012

\section{INTRODUCTION}

Sepsis is defined as the systemic inflammatory response to infection (Bone et al., 1992). Pathogen Associated Molecular Patterns (PAMPs) of microorganisms bind to Pattern Recognition Receptors (PRRs) found on the surface of cells of the immune system and release cytokines via induction of transcription factors (Bochud \& Calandra, 2003; Cinel \& Opal, 2009). Sepsis is characterized with over-secretion of proinflammatory cytokines including tumor necrosis factor (TNF), interleukin (IL) $1 \beta$ and High Mobility Group B1 DNA Binding (HMGB1); these cytokines trigger inflammatory response that induces local coagulation to limit tissue injury and also cause capillary leakage, tissue injury and organ failure (Ulloa \& Tracey, 2002). Cytokines activate coagu- lation by increasing the synthesis of tissue factor (TF) and prevent fibrinolysis by increasing the level of Plasminogen Activator Inhibitor Type-1 (PAI-1) in sepsis. Additionally, the levels of natural anticoagulants including anti-thrombin, protein $\mathrm{C}$ and tissue factor pathway inhibitor are decreased in sepsis (Cohen et al., 2002). All of these processes result in increased levels of intravascular fibrin and formation of microvascular thrombosis, thus ischemic multiple organ dysfunction leading to necrosis (Zeerleder et al., 2005). A frequent complication of sepsis is Disseminated Intravascular Coagulation (DIC) that arises from fibrin accumulation in small vessels and occlusion of capillaries with microthrombi (Peters et al., 2003). DIC is a clinical picture that includes consumption of platelets and disseminated hemorrhages without any laboratory tests to confirm or exclude its diagnosis (Levi et al., 2009).

HMGB1 is a DNA-associated nuclear protein that stabilize the nucleosome and take part in gene transcription (Lotze \& Tracey, 2005). Experimental models of sepsis have demonstrated that this is a cytokine expressed in the late term (Wang et al., 1999). HMGB-1 passively leaks from necrotic cells or is actively secreted by macrophages and neutrophils (Gibot \& Massin, 2007; Lotze \& Tracey, 2005). Literature studies have demonstrated that HMGB1 is associated with sepsis (Wang et al., 1999; Gibot et al., 2007; Gaini et al., 2007; Van Zoolen et al., 2007; Sunden-Cullberg et al., 2005; Karlsson et al., 2008), cell death (Lotze \& Tracey, 2005) DIC (Hatada et al., 2005), organ failure and mortality (Wang et al., 1999; Gibot et al., 2007; Hatada et al., 2005); however, there are also studies suggesting that HMGB1 is not associated with disease severity (Van Zoelen et al., 2007), or mortality (Gaini et al., 2007; Van Zoelen et al., 2007; Karlsson et al., 2008).

In this study besides coagulation tests, levels of HMGB1 were examined in groups of septic patients with and without DIC.

\section{MATERIALS AND METHODS}

Patients and setting. This study was conducted prospectively at Zonguldak Karaelmas University Hospital, a 524-bed referral and tertiary hospital. The hospital in-

\footnotetext{
e-mail: serefdenacikgoz@yahoo.com
}

Abbreviations: DIC, Disseminated Intravascular Coagulation; HMGB1, high mobility group B1 DNA binding; IL, interleukin; LRTI, lower respiratory tract infection; PAI-1, plasminogen activator inhibitor type-1; PAMPs, pathogen associated molecular patterns; PRRs, pattern recognition receptors; TF, tissue factor; TNF, tumor necrosis factor; UTI, urinary tract infection. 
Table 1. Classification of patients with sepsis, sepsis + DIC and ICU controls by etiology

\begin{tabular}{llll}
\hline ICU & control & Sepsis & Sepsis + DIC \\
\hline & $\mathrm{n}=20$ & $\mathrm{n}=21$ & $\mathrm{n}=12$ \\
\hline Lower respiratory tract infection & & 12 & 8 \\
Urınary tract infection & 4 & 4 \\
Peritonit & 2 & \\
Complicated skin and soft tissue infection & & 2 & \\
Source couldn't be find sepsis & & 1 & \\
Subarachnoid haemorrhage (SAH) & 4 & & \\
Traumatic SAH & 4 & & \\
GIS haemorrhage & 5 & & \\
Cerebrovascular accident & 5 & \\
Acute abdomen & 2 & \\
\hline
\end{tabular}

DIC were defined as group 1 (21 patients) and those developed sepsis with DIC were defined as group 2 (12 patients). Twenty patients admitted to the ICU without sepsis, DIC, malignancy or hemopoietic disorder were enrolled as ICU control group (group 3) and 20 healthy adult volunteers constituted the normal control group (group 4). The diagnoses of sepsis and DIC were established by the Department of Infectious Diseases using the diagnostic criteria of the International Sepsis Definitions Conference (Levy et al., 2003) and the International Society on Thrombosis and Haemostasis (ISTH) (Taylor et al., 2001). The study was approved by the hospital ethical board and informed cludes a 23-bed general ICU that admits surgical, medical and trauma patients. Patients admitted to the general ICU with the diagnosis of sepsis between January 1 st to December 31st, 2009 were included. Exclusion criteria were age $<16$ years, presence of malignancy or hemopoietic disorder. Patients who developed sepsis without consent was obtained from patients or their relatives.

Study procedures. Blood samples were obtained on the first day of sepsis/DIC diagnosis in septic patients with and without DIC and on the first day of hospital-

Table 2. HMGB-1 levels in patient and control groups

\begin{tabular}{lllll}
\hline & $\begin{array}{l}\text { Sepsis without DIC (group 1) } \\
\mathrm{n}=21\end{array}$ & $\begin{array}{l}\text { Sepsis with DIC (group 2) } \\
\mathrm{n}=12\end{array}$ & $\begin{array}{l}\text { ICU control (group 3) } \\
\mathrm{n}=20\end{array}$ & $\begin{array}{l}\text { Normal Control (group 4) } \\
\mathrm{n}=20\end{array}$ \\
\hline $\begin{array}{r}\text { HMGB-1 } \\
(\mathrm{ng} / \mathrm{ml})\end{array}$ & $28.42 \pm 7.37$ & $32.76 \pm 20.11$ & $16.73 \pm 4.31$ & $13.98 \pm 4.51$ \\
\cline { 2 - 5 } & $(18.31-42.59)$ & $(14.17-68.19)$ & $(9.61-24.71)$ & $(6.79-23.67)$ \\
\hline
\end{tabular}

Mean \pm S.D. $(\min -\max )$

Table 3. Markers of coagulation and WBC in patient and control groups

\begin{tabular}{|c|c|c|c|c|}
\hline & $\begin{array}{l}\text { Sepsis without DIC (group1) } \\
n=21\end{array}$ & $\begin{array}{l}\text { Sepsis with DIC (group2) } \\
\mathrm{n}=12\end{array}$ & $\begin{array}{l}\text { ICU control (group } 3 \text { ) } \\
\mathrm{n}=20\end{array}$ & Reference values \\
\hline \multirow{2}{*}{ PT (s) } & $21.09 \pm 8.53$ & $25.69 \pm 10.98$ & $18.93 \pm 4.78$ & \multirow{2}{*}{$12-18$} \\
\hline & $(13.9-51.1)$ & $(14.1-46.9)$ & $(13.1-35.7)$ & \\
\hline \multirow{2}{*}{ INR } & $1.452 \pm 0.653$ & $1.828 \pm 0.834$ & $1.332 \pm 0.393$ & \multirow{2}{*}{$<1.21$} \\
\hline & $(0.940-3.795)$ & $(0.960-3.454)$ & $(0.849-2.588)$ & \\
\hline \multirow{2}{*}{ aPTा (s) } & $37.39 \pm 7.74$ & $45.94 \pm 22.56$ & $29.72 \pm 6.01$ & \multirow{2}{*}{$22.6-35$} \\
\hline & $(25.7-53.4)$ & $(25.9-111.0)$ & $(20.1-43.5)$ & \\
\hline \multirow{2}{*}{ Fibrinogen (mg/dl) } & $630.81 \pm 154.09$ & $368.50 \pm 196.53$ & $381.95 \pm 134.05$ & \multirow{2}{*}{$175-400$} \\
\hline & $(328-974)$ & $(117-734)$ & $(136-553)$ & \\
\hline \multirow{2}{*}{ D-dimer (ng/ml) } & $2416.67 \pm 1631.60$ & $7200.00 \pm 10019.03$ & $723.50 \pm 920.41$ & \multirow{2}{*}{$<147$} \\
\hline & $(266-5800)$ & $(1170-38260)$ & $(46-3963)$ & \\
\hline Protein S (\%) & $\begin{array}{l}92.71 \pm 29.11 \\
(33-176)\end{array}$ & $\begin{array}{l}98.17 \pm 40.40 \\
(31-180)\end{array}$ & $\begin{array}{l}91.80 \pm 30.37 \\
(28-153)\end{array}$ & $55-160$ \\
\hline \multirow{2}{*}{ Protein C (\%) } & $62.48 \pm 23.64$ & $42.58 \pm 25.13$ & $84.05 \pm 24.66$ & \multirow{2}{*}{$70-130$} \\
\hline & $(26-121)$ & $(11-86)$ & $(44-139)$ & \\
\hline \multirow{2}{*}{$\begin{array}{l}\text { AT III } \\
(\%)\end{array}$} & $69.49 \pm 16.97$ & $53.42 \pm 16.15$ & $94.85 \pm 21.09$ & \multirow{2}{*}{$79-125$} \\
\hline & $(31-101)$ & $(34-82)$ & $(70-142)$ & \\
\hline \multirow{2}{*}{ WBC $(\mu l)^{-1}$} & $16585 \pm 8015$ & $12658 \pm 6180$ & $10375 \pm 3577$ & \multirow{2}{*}{$4800-10800$} \\
\hline & $(2800-30300)$ & $(3200-22100)$ & $(4300-17600)$ & \\
\hline \multirow{2}{*}{$\operatorname{PLT}(\mu \mathrm{l})^{-1}$} & $230238 \pm 184181$ & $66583 \pm 52330$ & $192300 \pm 67708$ & \multirow{2}{*}{$130000-400000$} \\
\hline & $(27000-866000)$ & (15000-194000) & (91000-322000) & \\
\hline
\end{tabular}

Mean \pm S.D. $(\min -\max )$ 
Table 4. Inter-group significance of differences of HMGB1 levels

\begin{tabular}{|c|c|c|c|c|c|c|}
\hline \multicolumn{7}{|l|}{ Groups } \\
\hline & $1-2$ & $1-3$ & $1-4$ & $2-3$ & $2-4$ & $3-4$ \\
\hline HMGB-1 & $p=0.213$ & $p<0.001$ & $p<0.001$ & $p<0.001$ & $p<0.001$ & $p=0.365$ \\
\hline
\end{tabular}

1, Sepsis without DIC; 2, Sepsis with DIC; 3, ICU control; 4, Normal control

ization in the control groups. Platelet and WBC were measured in complete blood, PT, aPTT, fibrinogen, Ddimer, protein $\mathrm{C}$, protein $\mathrm{S}$, and ATIII were measured in plasma and HMGB1 was measured in serum. Coagulation tests were performed on the day, the blood samples were drawn. Serum samples were stored at $-80^{\circ} \mathrm{C}$ for measurement of HMGB1.

Levels of HMGB1 were determined using the HMGB1 ELISA kit (Uscn Life Science Inc., Wuhan, China) with the sandwich method in an ELX 800 G ELISA device (BIO-TEC Instruments, Winooski, USA). Amax device (Trinity Biotech Plc, Bray, Co. Wicklow, Ireland) was used to determine PT, aPTT, fibrinogen, and protein $\mathrm{S}$ with the mechanic method and D-dimer, protein C, and ATIII with the optic method. Platelet (thrombocyte) and WBC count were measured in an LH 780 analyzer device (Beckman Coulter, Inc., Fullerton, USA). INR was calculated using the formula INR = (Patient PT/Normal PT ) ${ }^{\text {ISI }}$.

A normal PT value represents the average of mean normal PT range of the laboratory, whereas the International Sensitivity Index (ISI) is the correction coefficient of thromboplastin in commercial kits calculated according to international reference samples.

Statistical analysis. Inter-group differences were calculated by using Anova and Kruskal Wallis variance analyses and Mann-Whitney U-test. The KolmogorovSmirnov test was used to test the normality of distribu-

Table 5. Inter-group significance by coagulation markers

\begin{tabular}{|c|c|c|c|c|}
\hline & Groups & & & \\
\hline & $1,2,3$ & $1-2$ & $1-3$ & $2-3$ \\
\hline PT & $p=0.078$ & & & \\
\hline INR & $p=0.094$ & & & \\
\hline aPTा & $p=0.003$ & $p=0.059$ & $p=0.05$ & $p=0.001$ \\
\hline Fibrinogen & $p<0.001$ & $p<0.001$ & $p<0.001$ & $p=0.816$ \\
\hline D-dimer & $p<0.001$ & $p=0.024$ & $p<0.001$ & $p<0.001$ \\
\hline Protein S & $p=0.854$ & & & \\
\hline Protein C & $p<0.001$ & $p=0.028$ & $p=0.007$ & $p<0.001$ \\
\hline AT III & $p<0.001$ & $p=0.020$ & $p<0.001$ & $p<0.001$ \\
\hline WBC & $p=0.009$ & $p=0.088$ & $p=0.002$ & $p=0.321$ \\
\hline PLT & $p=0.003$ & $p=0.001$ & $p=0.340$ & $p=0.009$ \\
\hline
\end{tabular}

1, Sepsis without DIC; 2, Sepsis with DIC; 3 , ICU control tions. Statistical Package for Social Sciences (SPSS) version 18.0 was used.

\section{RESULTS}

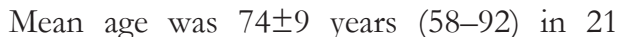
septic patients without DIC (group 1; 13

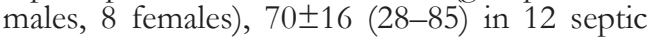
patients with DIC (group 2; 6 males, 6 fe-

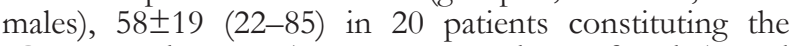
ICU control group (group 3; 14 males, 6 females), and $42 \pm 9.7$ in 20 healthy controls ( 7 males, 13 females).

The distribution of patients by the type of infection is demonstrated in Table 1 ; mean $\pm \mathrm{SD}$, minimum and maximum values of HMGB1 levels in groups 1, 2, 3 and 4 in Table 2, mean \pm S.D., minimum, maximum and reference values of PT, INR, aPT', fibrinogen, D-dimer, protein $\mathrm{S}$, protein $\mathrm{C}$, AT III activity, WBC and PLT counts are demonstrated in Table 3 , and significance of inter-group differences in these tests is shown in Tables 4 and 5.

The level of HMGB-1 was significantly increased in septic patients without DIC $(p<0.001, p<0.001)$ and with DIC $(p<0.001, p<0.001)$ compared, respectively, to the normal and ICU control groups. It was also higher in septic patients with DIC compared to septic patients without DIC; however, the difference was not statistically significant $(p=0.213)$. We also found that the HMGB1 levels of lower respiratory tract infection (LRTI) patients and urinary tract infection (UTI) patients sepsis without/ with DIC were significant higher than in the ICU and normal control group (Table 6,7) whereas the difference between the LRTI and UTI patients were not statistically significant in the no-DIC group or the DIC group $(p=0.212, p=0.283$ ) (Table 7).

Fibrinogen $(p<0.001)$, thrombocyte count $(p=0.001)$, ATIII $(p=0.020)$, and protein C $(p=0.028)$ were decreased, whereas D-dimer was increased $(p=0.024)$ in septic patients with DIC compared to septic patients without DIC (Table 3).

The aPTT $(p=0.002)$ and D-dimer $(p<0.001)$ levels of the mortal patients were higher than in the surviving patients. On the other hand, the anticoagulant parameters protein $\mathrm{C}(p=0.001)$ and ATIII $(p=0.002)$ activity of mortal patients were less than in the survivor group, whereas the difference in HMGB1 $(p=0.074)$ was not significant between the non-survivor and survivor patients (Table 8).

\section{DISCUSSION}

Sepsis is a systemic inflammatory response to infection and one of the causes of mortality in intensive care units (Peters et al., 2003). Molecular patterns of microorganisms attach to specific receptors on host cells and cause secretion of cytokines (Cinel \& Opal, 2009). TNF $\alpha$ and IL1 are early activators of the inflammatory cascade

Table 6. HMGB1 levels in subgroups

\begin{tabular}{lllllll}
\hline & $\begin{array}{l}\text { Sepsis without DIC } \\
\text { LRTI } \\
\mathrm{n}=12\end{array}$ & $\begin{array}{l}\text { Sepsis without DIC } \\
\text { UTI } \\
\mathrm{n}=4\end{array}$ & $\begin{array}{l}\text { Sepsis with DIC } \\
\text { LRTI } \\
\mathrm{n}=8\end{array}$ & $\begin{array}{l}\text { Sepsis with DIC } \\
\text { UTI } \\
\mathrm{n}=4\end{array}$ & $\begin{array}{l}\text { ICU control } \\
\mathrm{n}=20\end{array}$ & $\begin{array}{l}\text { Normal control } \\
\mathrm{n}=20\end{array}$ \\
\hline $\begin{array}{l}\text { HMGB1 } \\
\mathrm{ng} / \mathrm{ml}\end{array}$ & $29.48 \pm 7.60$ & $24.13 \pm 4.54$ & $26.44 \pm 17.15$ & $45.39 \pm 21.84$ & $16.73 \pm 4.31$ & $13.98 \pm 4.51$ \\
\cline { 2 - 8 } & $(18.31-41.11)$ & $(18.50-28.07)$ & $(14.17-68.18)$ & $(16.56-68.19)$ & $(9.61-24.71)$ & $(6.79-23.67)$ \\
\hline
\end{tabular}

Mean \pm S.D. (min-max). LRTI, lower respiratory tract infection; UTI, urinary tract infection 
Table 7. Significance of differences of HMGB1 levels between subgroups

\begin{tabular}{lll}
\hline HMGB1 & & \\
\hline Sepsis without DIC LRTI & ICU control & $p<0.001$ \\
Sepsis without DIC LRTI & Normal control & $p<0.001$ \\
Sepsis without DIC UTI & ICU control & $p=0.013$ \\
Sepsis without DIC UTI & Normal control & $p=0.002$ \\
Sepsis without DIC LRTI & Sepsis without DIC UTI & $p=0.212$ \\
Sepsis with DIC LRTI & ICU control & $p=0.016$ \\
Sepsis with DIC LRTI & Normal control & $p<0.001$ \\
Sepsis with DIC UTI & ICU control & $p=0.018$ \\
Sepsis with DIC UTI & Normal control & $p=0.007$ \\
Sepsis with DIC LRTI & Sepsis with DIC UTI & $p=0.283$ \\
\hline
\end{tabular}

LRTI, lower respiratory tract infection; UTI, urinary tract infection

in sepsis, whereas HMGB-1 and IL10 are late activators (Shimaoka \& Park., 2008). Cytokines released in sepsis trigger coagulation resulting in impairment of fibrinolytic and anticoagulant systems. Systemic intravascular fibrin accumulation leads to a frequent complication of DIC characterized with microvascular dysfunction and organ failures (Zeerleder et al., 2005).

Several studies have been performed on HMGB1 that is a cytokine taking part in septic process. Wang et al. (1999) used western immunoblotting to demonstrate HMGB1 secretion 6-8 hours after injection of lipopolysaccharide (LPS) to mice macrophage cultures. They reported that HMGB1 levels were increased in mice serum 8-32 hours following injection of endotoxins, and also that HMGB1 levels were increased in patients with sepsis compared to healthy controls. The increase was prominent in patients who died of sepsis compared to those who survived. In addition, organ function impairment has been reported in mice models of HMGB1 administration. Inhibition of HMGB1 with specific antibodies reduced the mortality in sepsis. According to those results it has been reported that HMGB1 is a cytokine of the late term in sepsis that is associated with mortality and organ dysfunction, and the latter has been associated with the toxic effect of the protein (Wang et al., 1999).

Gibot and coworkers (2005) investigated HMGB1 levels in patients with septic shock using the ELISA method and reported that increased HMGB1 levels were

Table 8. Coagulation markers, WBC and HMGB1 levels in nonsurvivor and survivor patients

\begin{tabular}{|c|c|c|c|}
\hline & $\begin{array}{l}\text { Sepsis without DIC+ } \\
\text { Sepsis with DIC + } \\
\text { ICU control } \\
\text { NONSURVIVOR } n=31\end{array}$ & $\begin{array}{l}\text { Sepsis without DIC+ } \\
\text { Sepsis with DIC+ } \\
\text { ICU control } \\
\text { SURVIVOR } n=22\end{array}$ & $\mathrm{p}$ value \\
\hline \multirow{2}{*}{ PT (s) } & $23.10 \pm 9.67$ & $18.79 \pm 4.95$ & \multirow{2}{*}{$p=0.099$} \\
\hline & $(13.9-51.10)$ & (13.10-35.70) & \\
\hline \multirow{2}{*}{ INR } & $1.64 \pm 0.74$ & $1.28 \pm 0.37$ & \multirow{2}{*}{$p=0.060$} \\
\hline & $(0.94-3.79)$ & $(0.85-2.59)$ & \\
\hline \multirow{2}{*}{ aPTT (s) } & $40.25 \pm 15.74$ & $31.04 \pm 6.74$ & \multirow{2}{*}{$p=0.002$} \\
\hline & $(22.3-111.0)$ & $(20.10-46.50)$ & \\
\hline \multirow{2}{*}{ Fibrinogen (mg/dl) } & $490.83 \pm 199.53$ & $458.72 \pm 201.45$ & \multirow{2}{*}{$p=0.279$} \\
\hline & $(117-896)$ & $(136-974)$ & \\
\hline \multirow{2}{*}{ D-dimer (ng/ml) } & $4258.03 \pm 6673.0$ & $891.86 \pm 795.79$ & \multirow{2}{*}{$\mathrm{p}<0.001$} \\
\hline & $(102.0-38260.0)$ & $(46.0-2979.0)$ & \\
\hline \multirow{2}{*}{ Protein S (\%) } & $96.93 \pm 34.78$ & $88.90 \pm 27.28$ & \multirow{2}{*}{$p=0.522$} \\
\hline & $(31.0-180.0)$ & $(28.0-153.0)$ & \\
\hline \multirow{2}{*}{ Protein C (\%) } & $56.23 \pm 28.62$ & $80.04 \pm 23.01$ & \multirow{2}{*}{$p=0.001$} \\
\hline & $(11.0-132.0)$ & $(34.0-139.0)$ & \\
\hline \multirow{2}{*}{ AT III (\%) } & $66.75 \pm 22.26$ & $87.63 \pm 22.56$ & \multirow{2}{*}{$p=0.002$} \\
\hline & $(31-129)$ & $(47-142)$ & \\
\hline \multirow{2}{*}{ WBC $(\mu \mathrm{l})^{-1}$} & $14306 \pm 7621$ & $12009 \pm 5071$ & \multirow{2}{*}{$p=0.299$} \\
\hline & $(2800-30300)$ & $(4300-22400)$ & \\
\hline \multirow{2}{*}{$\operatorname{PLT}(\mu \mathrm{l})^{-1}$} & $167161 \pm 167049$ & $195363 \pm 86903$ & \multirow{2}{*}{$p=0.072$} \\
\hline & $(15000-866000)$ & $(42000-360000)$ & \\
\hline \multirow{2}{*}{ HMGB-1 (ng/ml) } & $27.58 \pm 14.05$ & $21.34 \pm 9.26$ & \multirow{2}{*}{$p=0.074$} \\
\hline & $(13.37-68.19)$ & $(9.61-42.59)$ & \\
\hline
\end{tabular}

Mean \pm S.D. (min-max) 
associated with the severity of septic shock with higher levels being observed at day 3 in patients who died compared to those who survived. That result has been associated with the formation of acute tissue injury with the pro-inflammatory effect of HMGB1.

In their study, Hatada and coworkers (2005) determined that HMGB1 was higher in ICU patients with infection, tumor or trauma compared to normal controls, the rate of development of DIC was associated with increased levels of HMGB1, and that highest levels of HMGB1 were determined in patients with organ failure and patients that died. Those investigators have suggested that HMGB1 might be a proper prognostic marker of DIC.

Levels of HMGB1 have been found significantly increased in patients with sepsis and infection without SIRS (Systemic Inflammatory Response Syndrome) compared to healthy controls, in severe sepsis compared to sepsis, and in bacteraemic patients compared to nonbacteraemic patients in another study performed with 154 patients using the ELISA kit. Levels were lower in septic shock compared to severe sepsis; however, the difference was not statistically significant. It was concluded that levels of HMGB1 correlated with other proinflammatory cytokines and disease severity, but not with mortality. That result was associated with the pro- inflammatory effect of HMGB1 (Gaini et al., 2007).

Van Zoelen and coworkers (2007) investigated HMGB1 levels in patients with sepsis secondary to urinary infection, peritonitis and pneumonia using ELISA at day 0 and 3 . They reported that the secretion of HMGB1 was delayed in sepsis secondary to urinary system infections compared to sepsis secondary to pneumonia and peritonitis, and that the kinetics of HMGB1 release were altered by the source of infection. HMGB1 was not associated with mortality and disease severity in that study.

Sunden-Cullberg and coworkers (2005), measured the level of HMGB1 in patients with severe sepsis and septic shock using western immunoblotting with two separate methods using different antibodies. In that study, HMGB1 remained elevated for a week and was a late marker of inflammation. According to one of the methods HMGB1 was decreased in dead subjects, whereas the other method demonstrated no differences. That discrepancy was attributed to the use of different subunits in measuring biological activity in those methods, or to interference due to inhibiting factors in serum.

In a study performed on ICU patients with severe sepsis blood samples were drawn at day 0 and 3 to determine levels of HMGB1 both with western immunoblotting and ELISA methods. Those authors determined that HMGB1 was increased compared to healthy controls; however, there was no difference between dead and alive patients with sepsis. It has been concluded that HMGB1 is not a marker of mortality. HMGB1 was lower at 72 hours compared to day 0 in patients with severe cardiovascular and hematological failure, possibly because of the emergence of apoptotic rather than necrotic cell death in certain patients (Karlsson et al., 2008).

Our results indicated that HMGB1 level was increased in sepsis without DIC compared to the controls conforming to the results of other studies indicating increased HMGB1 in sepsis as a pro-inflammatory marker (Wang et al., 1999; Gibot et al., 2007; Gaini et al., 2007; Van Zoolen et al., 2007; Sunden-Cullberg 2005; Karlsson et al., 2008). HMGB1 was significantly higher in the group of patients with sepsis + DIC compared to normal and ICU controls in our study; however, no significant increase could be determined in patients with sepsis + DIC compared to those with sepsis alone. Our results differed from those of Hatada et al. (2005) who have demonstrated that HMGB1 levels are significantly elevated in ICU patients with DIC.

Other studies have reported that the variability in HMGB1 levels might be associated with apoptotic cell death or necrosis (Karlsson et al., 2008), or determination of different biological forms of HMGB1 in the improved immunological kits (Sunden-Cullberg et al., 2005). Additionally, Van Zoolen et al. (2007) have reported that the kinetics of HMGB1 accumulation varies by the source of infection and that this is not associated with disease severity and mortality.

In our study there was no difference in HMGB1 levels obtained within the first day of diagnosis between the non-surviving and surviving patients. Contrary to this finding, Wang et al. (1999), Gibot et al. (2007), Hatada et al. (2005) reported higher HMGB1 levels in mortal patients. Different from our study, in Hatada et al. (2005) study there were patients with neoplasms. Gibot et al. (2007) reported high levels of HMGB1 on the third day. Wang et al. (1999) reported that HMGB1 is a late mediator of endotoxin lethality in mice. SundenCullberg et al. (2005) used two methods different from our study and they found lower levels of HMGB1 in nonsurvivors compared to survivors, but the measurement with a second method gave similar results in both groups. Our results are compatible with those of Gaini et al. (2007), Van Zoolen et al. (2007), Karlsson et al. (2008) who found no relation with mortality. aPTT and fibrin degradation products D-dimer levels of the nonsurvivor patients were higher than in survivor patients, also anticoagulant protein C and ATIII activity were lower in nonsurvivor patients. At the first day of diagnosis significant differences in fibrinogen and platelets were not detected when comparing nonsurvivors and survivors. Van Zoolen et al. (2007) reported that in severe sepsis the kinetics of HMGB1 accumulation may differ depending on the primary source of infection. In our study there were no significant difference in HMGB1 levels between lower respiratory tract infection and urinary tract infection patients in regard to the etiology of sepsis. Unfortunately, the size of the population in our subgroups is small which limits our study.

Unlike in the study of Hatada et al. (2005), patients with hematopoietic diseases and solid tumors were excluded from our study. HMGB1 expression has been reported to be increased in several types of cancer cells (Lotze \& Tracey, 2005), breast (Flohr et al., 2001), colon (Völp et al., 2006) and melanoma (Poser et al., 2003) cancers, suggesting that the pathology leading to the development of DIC might influence the level of HMGB1.

Consequently, similar to the literature data (Levi et al., 2009; Mujun et al., 2000; Fourrier et al., 1992) also in our patients the levels of fibrinogen, ATIII, protein C and thrombocyte count were significantly decreased, whereas D-dimer was significantly increased in septic cases with DIC compared to those without DIC. In the view of our findings measuring levels of HMGB1, might remain inadequate in determining the development of DIC in patients with sepsis.

\section{REFERENCES}

Bochud PY, Calandra T (2003) Pathogenesis of sepsis: new concepts and implications for future treatment. BMJ 326: 262-266.

Bone RC, Balk RA, Cerra FB, Dellinger RP, Fein AM, Knaus WA, Schein RM, Sibbald WJ (1992) ACCP/SCCM Consensus Confer- 
ence: Definitions for sepsis and organ failure and guidelines for the use of innovative therapies in sepsis. Chest 101: 1644-1655.

Cinel I, Opal SM (2009) Molecular biology of inflammation and sepsis: a primer. Crit Care Med 37: 291-304.

Cohen J (2002) The immunopathogenesis of sepsis. Nature 420:885891.

Flohr AM, Rogalla P, Meiboom M, Borrmann L, Krohn M, ThodeHalle B et al (2001) Variation of HMGB1 expression in breast cancer. Anticancer Res 21: 3881-3885.

Fourrier F, Chopin C, Goudemand J, Hendrycx S, Caron C, Rime A. et al (1992) Septic shock, multiple organ failure and disseminated intravascular coagulation compared patterns of antithrombin III, protein $\mathrm{C}$ and protein S deficiencies. Chest 101: 816-823.

Gaini S, Koldkjaer OG, Møller HJ, Pedersen C, Pedersen SS (2007) A comparison of high-mobility group-box 1 protein, lipopolysaccharide-binding protein and procalcitonin in severe communityacquired infections and bacteraemia: a prospective study. Crit Care 11: R76.

Gibot S, Massin F, Cravoisy A, Barraud D, Nace L, Levy B et al (2007) High-mobility group box 1 protein plasma concentrations during septic shock. Intensive Care Med 33: 1347-1353.

Hatada T, Wada H, Nobori T, Okabayashi K, Maruyama K, Abe Y et al (2005) Plasma concentrations and importance of High Mobility Group Box protein in the prognosis of organ failure in patients with disseminated intravascular coagulation. Thromb Haemost 94: 975-979.

Karlsson S, Pettilä V, Tenhunen J, Laru-Sompa R, Hynninen M, Ruokonen E (2008) HMGB1 as a predictor of organ dysfunction and outcome in patients with severe sepsis. Intensive Care Med 34: 1046-1053.

Levy MM, Fink MP, Marshall JC, Abraham E, Angus D, Cook D et al. (2003) 2001 SCCM/ESICM/ACCP/ATS/SIS International sepsis definitions conference. Intensive Care Med 29: 530-538.

Levi M, Toh CH, Thachil J, Watson HG (2009) Guidelines for the diagnosis and management of disseminated intravascular coagulation. British Committee for Standards in Haematology. $\mathrm{Br} J$ Haematol 145: 24-33.

Lotze MT, Tracey KJ (2005) High-mobility group box 1 protein (HMGB1): nuclear weapon in the immune arsenal. Nat Rev Immunol 5: $331-342$
Mujun Y, Nardella A, BS, MT(ASCP), SH; Pechet L (2000) Screening tests of disseminated intravascular coagulation: Guidelines for rapid and specific laboratory diagnosis. Crit Care Med 28: 1777-1780

Peters K, Unger RE, Brunner J, Kirkpatrick CJ (2003) Molecular basis of endothelial dysfunction in sepsis. Cardiovasc Res 60: 49-57.

Poser I, Golob M, Buettner R, Bosserhoff AK (2003) Upregulation of HMG1 leads to melanoma inhibitory activity expression in malignant melanoma cells and contributes to their malignancy phenotype. Mol Cell Biol 23: 2991-2998.

Shimaoka M, Park EJ. (2008) Advances in understanding sepsis. Eur J Anaesthesiol Suppl 42: 146-53.

Sundén-Cullberg J, Norrby-Teglund A, Rouhiainen A, Rauvala H, Herman G, Tracey KJ et al (2005) Persistent elevation of high mobility group box-1 protein (HMGB1) in patients with severe sepsis and septic shock. Crit Care Med 33: 564-573.

Taylor FB Jr, Toh CH, Hoots WK, Wada H, Levi M (2001) Towards definition, clinical and laboratory criteria, and a scoring system for disseminated intravascular coagulation. Scientific Subcommittee on Disseminated Intravascular Coagulation (DIC) of the International Society on Thrombosis and Haemostasis (ISTH). Thromb Haemost 86: $1327-1330$.

Ulloa L, Tracey KJ (2005) The 'cytokine profile': a code for sepsis. Trends Mol Med 11: 56-63.

Van Zoelen MA, Laterre PF, Van Veen SQ, Van Till JW, Wittebole $\mathrm{X}$, Bresser $\mathrm{P}$ et al (2007) Systemic and local high mobility group box 1 concentrations during severe infection. Crit Care Med 35: 2799-2804.

Völp K, Brezniceanu ML, Bösser S, Brabletz T, Kirchner T, Göttel $\mathrm{D}$ et al (2006) Increased expression of high mobility group box 1 (HMGB1) is associated with an elevated level of the antiapoptotic c-IAP2 protein in human colon carcinomas. Gut 55: 234-242.

Wang H, Bloom O, Zhang M, Vishnubhakat JM, Ombrellino M, Che $\mathrm{J}$ et al (1999) HMG-1 as a late mediator of endotoxin lethality in mice. Science 285: 248-251.

Zeerleder S, Hack CE, Wuillemin WA (2005) Disseminated intravascular coagulation in sepsis. Chest 128: 2864-2875. 